University of Nebraska - Lincoln

DigitalCommons@University of Nebraska - Lincoln

2009

\title{
Early speech motor development: Cognitive and linguistic considerations
}

Ignatius S. B. Nip

San Diego State University

Jordan R. Green

University of Nebraska-Lincoln, jgreen4@unl.edu

David B. Marx

University of Nebraska-Lincoln, david.marx@unl.edu

Follow this and additional works at: https://digitalcommons.unl.edu/specedfacpub

Part of the Special Education and Teaching Commons

Nip, Ignatius S. B.; Green, Jordan R.; and Marx, David B., "Early speech motor development: Cognitive and linguistic considerations" (2009). Special Education and Communication Disorders Faculty Publications. 4.

https://digitalcommons.unl.edu/specedfacpub/4

This Article is brought to you for free and open access by the Department of Special Education and Communication Disorders at DigitalCommons@University of Nebraska - Lincoln. It has been accepted for inclusion in Special Education and Communication Disorders Faculty Publications by an authorized administrator of DigitalCommons@University of Nebraska - Lincoln. 


\title{
Early speech motor development: Cognitive and linguistic considerations
}

\author{
Ignatius S. B. Nip, ${ }^{1}$ Jordan R. Green, ${ }^{2}$ and David B. Marx ${ }^{3}$ \\ ${ }^{1}$ School of Speech, Language, \& Hearing Sciences, San Diego State University, \\ 5500 Campanile Dr., San Diego, CA 92182-1518, USA \\ ${ }^{2}$ Department of Special Education and Communication Disorders, \\ University of Nebraska-Lincoln, Lincoln, NE, USA \\ ${ }^{3}$ Department of Statistics, University of Nebraska-Lincoln, Lincoln, NE, USA \\ Corresponding author - I. S. B. Nip; fax 619 594-7109, email inip@mail.sdsu.edu
}

\begin{abstract}
This longitudinal investigation examines developmental changes in orofacial movements occurring during the early stages of communication development. The goals were to identify developmental trends in early speech motor performance and to determine how these trends differ across orofacial behaviors thought to vary in cognitive and linguistic demands (i.e., silent spontaneous movements, babble, and first words). Movements of the lower lip and jaw were recorded using a three-dimensional motion capture system. Twenty-four infants were observed every 3 months, from 9 to 21 months of age. Jaw and lower lip speed, and lower lip range of movement increased with age. Silent spontaneous movements were consistently slower than words, whereas kinematic measures associated with babble did not differ from those associated with words. These findings suggest that speech movements may reflect linguistic and cognitive processing demands and that the continuity hypothesis between babbling and words may also be observed at the kinematic level.

Learning outcomes - Readers will be able to: (1) describe the potential role of cognition and language in early speech development, (2) describe kinematic changes in the orofacial system from 9 to 21 months of age, and (3) identify the differences in kinematic characteristics for silent spontaneous orofacial movements, babbles and words between 15 to 21 months of age.
\end{abstract}

Keywords: speech motor development, speech, kinematics

\section{Introduction}

The current longitudinal investigation examines early speech motor development at the ages when children are rapidly acquiring new speech, language, and cognitive skills. Although the number of longitudinal descriptions of speech motor skill development is limited, existing theories and cross-sectional data suggest that speech development is a nonlinear process marked with steep increases, plateaus, and regressions (Green \& Nip, in press; Kent, 1992; Thelen, 1991). These nonmontonic changes are thought to reflect environmental influences as well as developmental interactions among emerging skills for cognition, language, affect, and motor control (Smith \& Goffman, 2004; Thelen, 1991). For example, Dynamic Systems Theory predicts that regressions in motor performance coincide with the emergence of new behaviors or skills (Case-Smith, 1996; Lewis, 2000]). Recently, Green and Nip (in press) proposed that, at various points in development, constraints in early oral motor skills may limit the rate at which infants and young 
children acquire new speech sounds, whereas emerging cognition and language skills may act as catalysts to slowly emerging speech motor skills, initially causing a regression or plateaus in articulatory development but ultimately accelerating its growth.

\subsection{Speech motor development}

Previous investigations support the suggestion that limited oral motor and articulatory control may constrain early speech development and restrict phonetic inventories. For example, the infant's limited phonetic repertoire is restricted to phonemes that can be produced primarily with the jaw (Kent, 1999; MacNeilage, Davis, Kinney, \& Matyear, 2000); infants may rely on jaw movements because they appear to have limited control over the lips and tongue for producing sounds (Green, Moore, Higashikawa, \& Steeve, 2000; Green, Moore, \& Reilly, 2002). However, the production of the full range of sounds in English requires lower lip and tongue movements that are independent from those of the underlying jaw. Another potential articulatory constraint in early speech includes the limited abilities to coordinate the movements of the lower lip with the jaw and to independently move the upper and lower lips. These constraints may explain, for example, why labiodental fricatives do not tend to appear before the age of 2 years (Green et al., 2000).

\subsection{Cognition and language}

Although poor oral motor control may constrain early speech production, cognitive and linguistic skills may act as catalysts to affect the rate of speech development. For instance, toddlers with larger vocabularies have fewer phonological errors (Smith, McGregor, \& Demille, 2006) and conversely, children with expressive language delay have restricted consonantal inventory as compared to their typically developing peers (Carson, Klee, Carson, \& Hime, 2003; Paul \& Jennings, 1992; Rescorla \& Ratner, 1996; Whitehurst, Smith, Fischel, Arnold, \& Lonigan, 1991). These findings suggest that having advanced language skills may facilitate the development of essential speech motor skills.

Studies of children and adults provide additional evidence of links between cognitive and linguistic processing demands and speech motor performance. For example, a transient dip in lip and jaw movement stability has been observed at 2 years of age (Green et al., 2002), which is during the period when children are typically making rapid gains in phonology and expressive language. In studies on adults, the variability of speech movements increases in a syntactically complex sentence as compared to simple sentences (Kleinow \& Smith, 2006) and while concurrently performing visumotor task (Dromey \& Bates, 2005). In addition, the maximum speeds of the lower lip and jaw are slower for speaking tasks requiring less cognition and language formulation needs, such as a diadochokinetic task, as compared to tasks requiring more, such as retelling a story (Nip \& Green, 2006).

These findings underscore that a comprehensive understanding of speech development requires a better understanding of the influences of emerging cognitive and language skills on speech motor control. One way to examine these relations in early childhood is to characterize changes in oral motor performance in infants as they transition from producing silent spontaneous movements to babbling and, finally, to words (Steeve, Moore, Green, Reilly, \& Ruark McMurtrey, 2008). This transition represents a shift from orofacial behaviors that require little or no cognitive and linguistic processing to behaviors that involve phonology, semantics, and communicative intent.

Spontaneous movements are the result of phasic and global excitation of motor circuits in the central nervous system (Hayes \& Mitchell, 1998) and therefore require little or no cognitive and linguistic processing. These movements begin prenatally (Lopez Ramon \& Cajal, 1996) and continue through the first year of life.

Babbling, which begins at 7 months of age, involves the production of adult-like vowels and consonants (Oller, 2000). Babbling is similar to silent spontaneous movements in that both presumably lack articulatory targets (Sussman, Minifie, Buder, Stoel-Gammon, \& Smith, 1996). However, one major distinction between silent spontaneous oral movements and babble is that babbling integrates orofacial movements with respiratory and phonatory movements to produce adult-like speech sounds (Oller, 2000).

In contrast to silent spontaneous movements and babbles, words require more cognitive and linguistic processing. Although infants tend to use the same sounds in babbling and words, words require specific phonemic targets (Stoel-Gammon, 1998), indicate communicative intent (Whitehurst et al., 1991), and have associated meaning (McShane, 1980). 


\subsection{Purpose}

Little is known about the relations between early oral motor control, cognition, and language. Previous kinematic work examining orofacial behaviors in young infants have been cross-sectional and narrowly focused on specific orofacial behaviors such as silent spontaneous movements (Green \& Wilson, 2006) or babble (Green et al., 2000; Green et al., 2002]). The current investigation addresses the following questions:

1. What are the age-related changes in kinematic characteristics (speed, range of movement) of orofacial behaviors during early language acquisition?

2. How do kinematic characteristics of various orofacial behaviors (e.g., silent spontaneous movements, babbles, words) in early language development differ?

\section{Method}

\subsection{Participants}

A sample of 24 infants (11 males, 13 females) was studied every 3 months from 9 to 21 months of age. The infants were born at term with no neurological, vision, hearing, or physical impairments. All of the infants lived in the Midwest and were members of monolingual English-speaking families.

\subsection{Recording orofacial behaviors}

Orofacial behaviors of the infants were recorded noninvasively using an eight-camera motion capture system (Motion Analysis, Ltd.). The infant sat in a car seat facing their caregiver and the optical motion capture system. Fifteen flat circular markers were placed on each infant's face, as shown in Figure 1. Markers were placed above each eyebrow, on the bridge of the nose and one on the nose tip. A reflective marker was placed on the upper lip (vermillion border), and one on the lower lip, directly below the upper lip marker. Markers were placed at the corners of the mouth, at the oral commissure. Three markers were placed on the jaw, one at the center (mental protuberance) and one on each side a couple of centimeters to the left and right, above the platysma. A rigid head marker, which housed four reflective markers and the

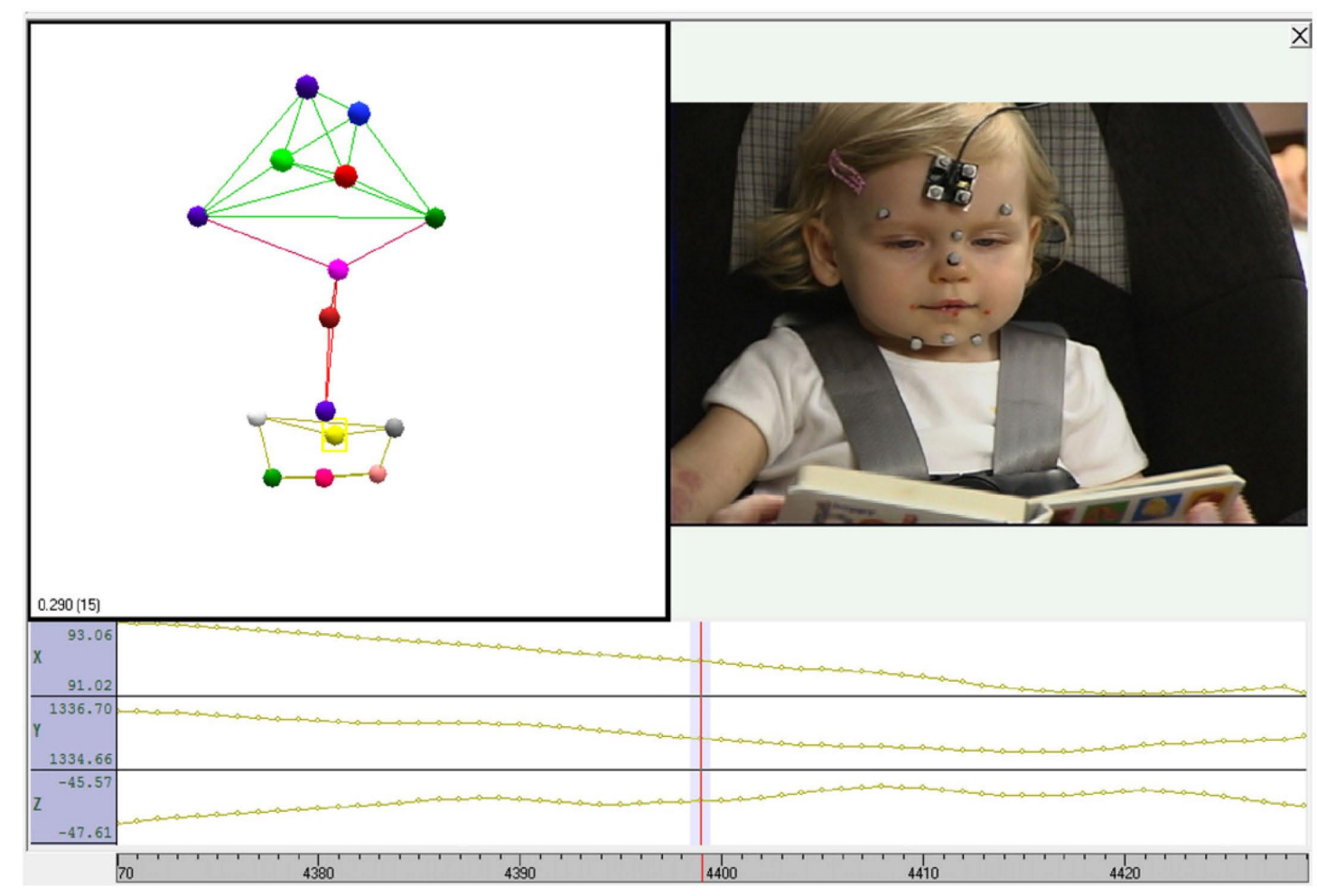

Figure 1. Reflective marker set on a 15-month-old participant and movement trace of the lower lip marker. 
microphone that was used to obtain acoustic recordings, was placed on the central forehead, at the hairline. This head marker was later used to subtract head movement from the other markers.

The infant was placed in front of the motion capture system. The infant's primary caregiver, who was typically the mother, sat in front of the child. Each parent-infant dyad was given different sets of toys provided throughout the session. These sets of toys were designed to elicit requesting, joint attention and social interaction.

\subsection{Data parsing and quantitative analyses of movements}

The continuous recordings of facial movements were separated into epochs. Movement epochs were considered to be separate if there no movement was observed on the video captured for $500 \mathrm{~ms}$ or longer. All movement traces were low-pass filtered $\left(F_{\mathrm{LP}}=10 \mathrm{~Hz}\right)$ prior to analysis.

Trained transcribers then determined if a movement epoch was a silent spontaneous movement, vocalization, babble, word, or phrase. Only silent spontaneous movements, babbles, and words were investigated. Vegetative behaviors (e.g., laughing, crying, hiccups, etc.) were discarded from the corpus. Movement epochs that did not have an associated vocalization were considered to be silent spontaneous movements. Utterances consisting of a vowel or an adult-like vowel were coded as vocalizations. An utterance was considered babble if it had an adult-like consonant and had no apparent meaning. An utterance was determined to be a word if it was adult-like in form, with one or no speech sound errors in an utterance with less than three segments or two or fewer speech sound errors in an utterance with four segments or more. Utterances that appeared to have meaning but were not adult-like in form or had more speech errors were coded as possible words and not included in the analyses. Utterances consisting of two or more words were coded as phrases. The transcribers reached inter-reliability of $89.4 \%$ on coding movement epochs produced in 10 randomly selected sessions.

Custom Matlab algorithms were used to analyze movement epochs. The algorithms calculated the Euclidean distance of the lower lip and jaw markers during the movement epoch, as shown in Figure 2. The algorithms then determined maximum speed of movement and range of movement, defined as the difference between the maximum and minimum Euclidean distance from the head marker, for the opening and closing gestures of the lower lip and jaw markers.

\subsection{Statistical analyses}

To screen for outliers, opening and closing speed and range of movement values for the jaw and lower lip marker during each movement epoch were examined to determine if the observations fell within the normal distribution. Least-square means were calculated by age and orofacial behavior. Residuals for speed and range of movement of each epoch were calculated and then fit in a normal curve. Observations that fell outside of the normal curve were removed. A total of 41 observations out of 8872 movement epochs were removed in this procedure.

To examine age-related changes of speed and range of movement of the lower lip and the jaw, all orofacial behaviors were pooled from each data collection session. Means of maximum opening speed, closing speed and range of movement for each marker of each participant during each session were taken. Simple regressions were conducted for each kinematic variable using age as a predictor. Based on prior findings (Green \& Wilson, 2006) articulatory movement speed was expected to increase gradually with age. Plateaus in articulatory speed, however, were expected to occur at one and two years of age, when children typically begin to rapidly acquire new vocabulary.

To determine if kinematic differences existed between orofacial behaviors, analysis of covariance (ANCOVA) models were estimated to examine the overall pattern and individual differences in the development of jaw speed during different orofacial behaviors (i.e., silent spontaneous movements, babbles, words) across age. The ANCOVA was conducted using age as a covariate.

\section{Results}

\subsection{Age effects}

The proportion of orofacial behaviors recorded at each age is reported in Figure 3. These data indicate that the children produced a wide range of orofacial behaviors at each age, which might be assumed to vary in their demands on cognitive and linguistic processing. 

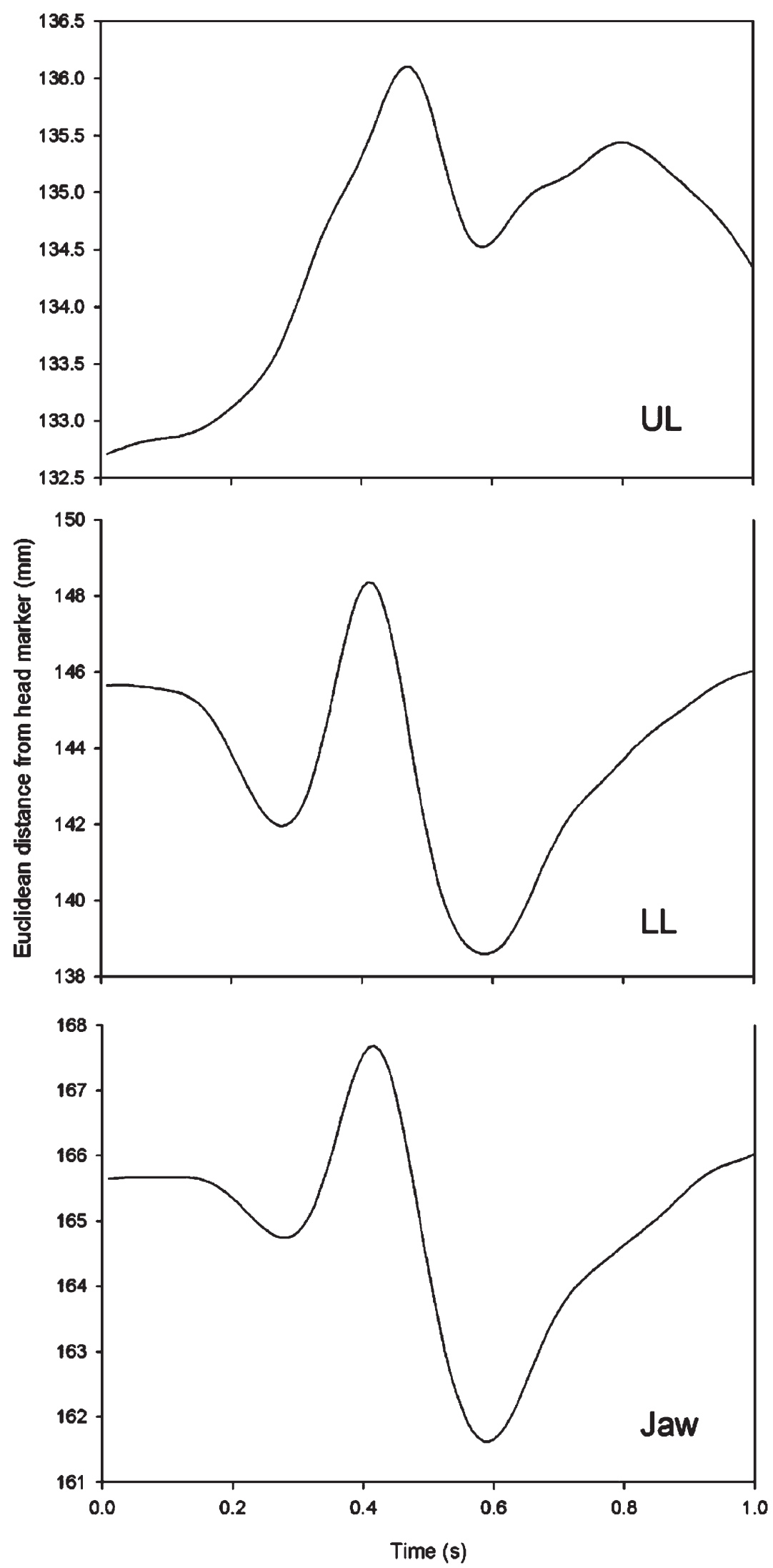

Figure 2. Output of Matlab algorithms showing movement traces of the upper lip, lower lip and jaw after head movement has been subtracted out. 


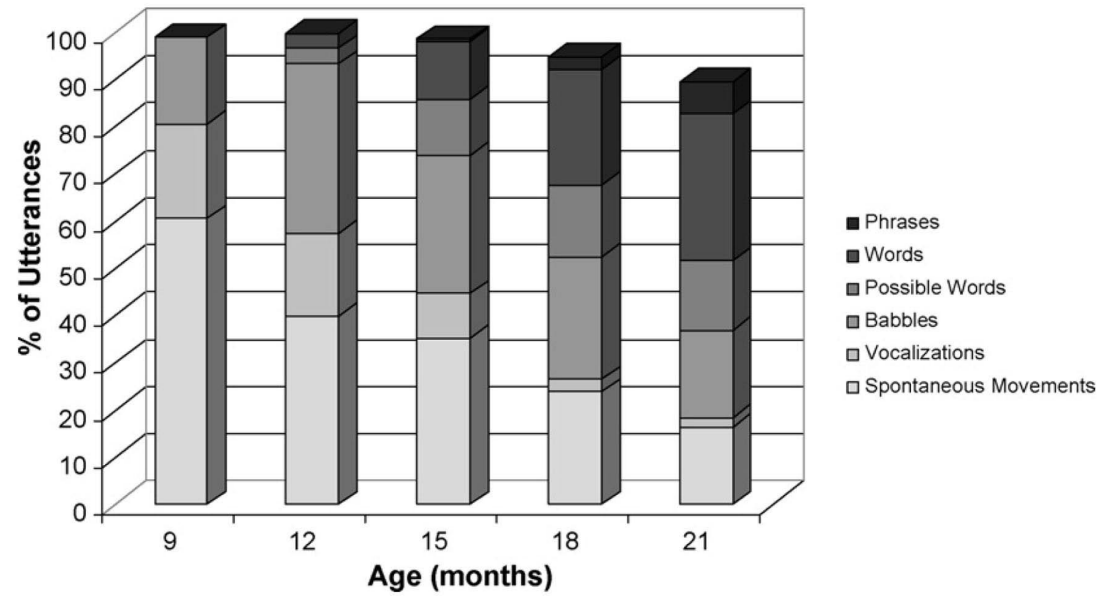

Figure 3. Percentage of orofacial behaviors (spontaneous movement, vocalizations, babbles, possible words, words, and phrases) $(n=24)$.

\subsubsection{Jaw marker}

Age and maximum closing speed had a weak relationship $\left[F(1,99)=11.68, p<.001, b=1.00, R^{2}=.11\right]$. There was a weak relationship between age and maximum opening speed $[F(1,99)=8.94, p=.003$, $\left.b=-.92, R^{2}=.08\right]$. Range of movement for the jaw and age did not have a significant linear relationship $[F(1,99)=.94, p>.05]$. Figure 4 shows the developmental course of the jaw speed variables from 9 to 21 months.

\subsubsection{Lower lip marker}

Maximum closing velocity $[F(1,77)=21.74, p<.001]$, maximum opening velocity $[F(1,77)=6.84, p=.01]$, and range of movement for the lower lip marker increased with age $[F(1,77)=8.71, p=.004]$. Figure 5 shows the change in speed variables from 9 to 21 months for the lower lip and Figure 6 shows the change in range of movement.

\subsection{Behavior effects}

To determine if the trajectories for speed differ among orofacial behaviors, ANCOVAs were conducted with age centered at 21 months. Only closing speed analyses are reported because analyses examining

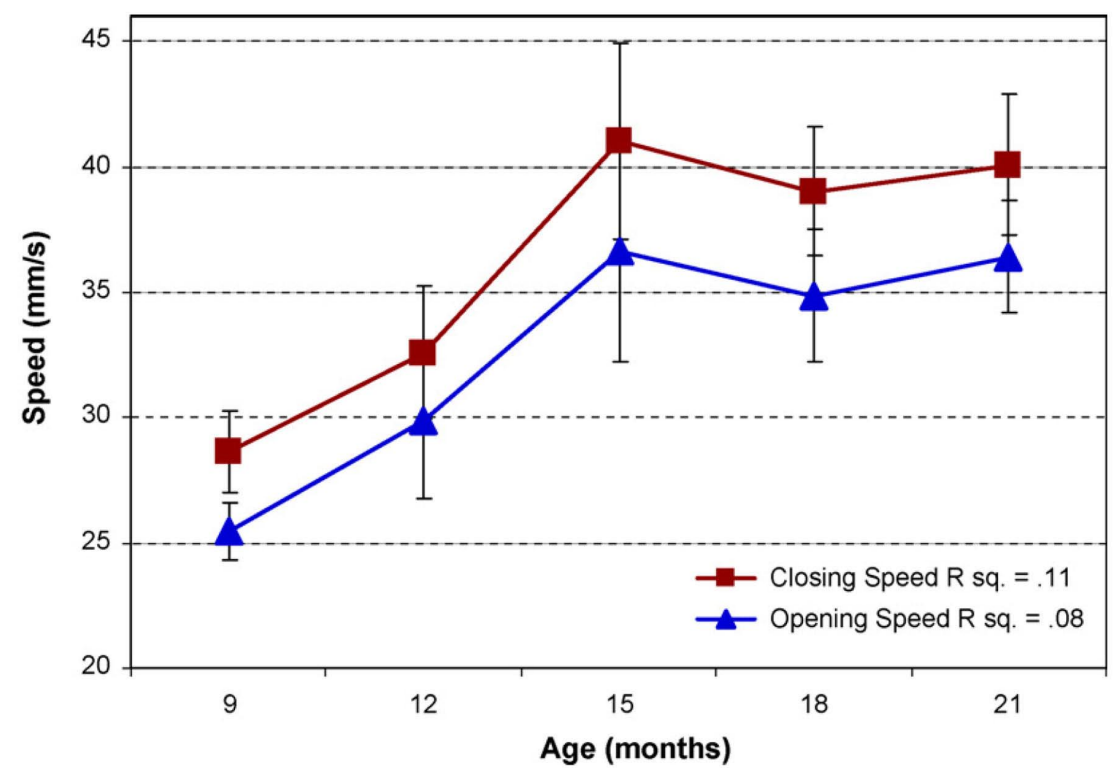

Figure 4. Speed of the jaw marker from 9 to 21 months $(n=24)$. 


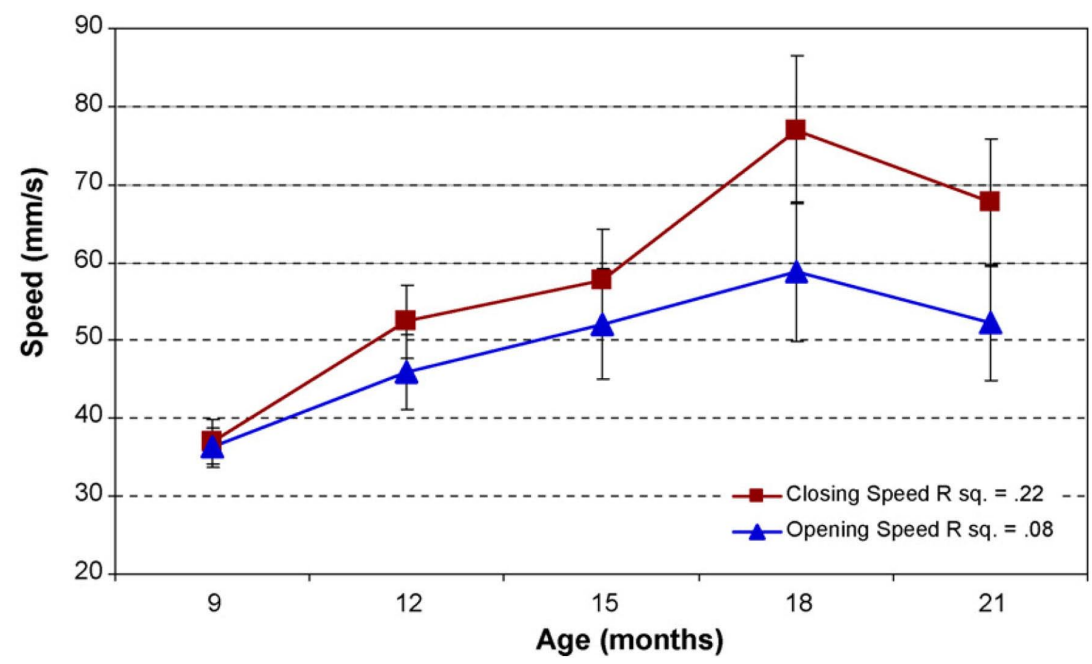

Figure 5. Speed of the lower lip marker from 9 to 21 months $(n=24)$.

opening speed were very similar. Jaw closing speed was predicted from age and orofacial behavior (i.e., silent spontaneous movements, babbles, and words). Only data from 15 to 21 months was used as those were the only ages at which all three orofacial behaviors were produced. Because of missing data, only 15 participants were included in the ANCOVA for the lower lip marker. Missing data for this marker occurred for a variety of reasons including being pulled off by participants, mistracking due to reduced reflectivity secondary to saliva, and occlusion of the marker from the view of camera by the participants' hand or a toy.

\subsubsection{Jaw marker closing speed}

Figure 7 illustrates the closing speed of the jaw for silent spontaneous behaviors, babbles and words from 15 to 21 months. The results for the ANCOVA on closing speed are presented in Table 1 and Table 2. The main effect of age was marginally significant $[F(1,154)=3.61, p=.06]$. The main effect for orofacial behavior $[F(2,154)=8.04, p=.0008]$ was also significant. Silent spontaneous movements were significantly slower than words $(t=-2.57, p=.01)$ by $16.05 \mathrm{~mm} / \mathrm{s}$ at the age of 21 months; no significant difference was found between babbling and words. The age $\times$ orofacial behavior interaction was not significant.

\subsubsection{Lower lip marker closing speed}

Figure 8 illustrates the closing speed of the lower lip marker for silent spontaneous behaviors, babbles and words from 18 to 21 months. The results for the ANCOVA on closing speed are presented in Table 3 and 4 . The main effect of age was not significant. The main effect for orofacial behavior $[F(2,46)=13.48$,

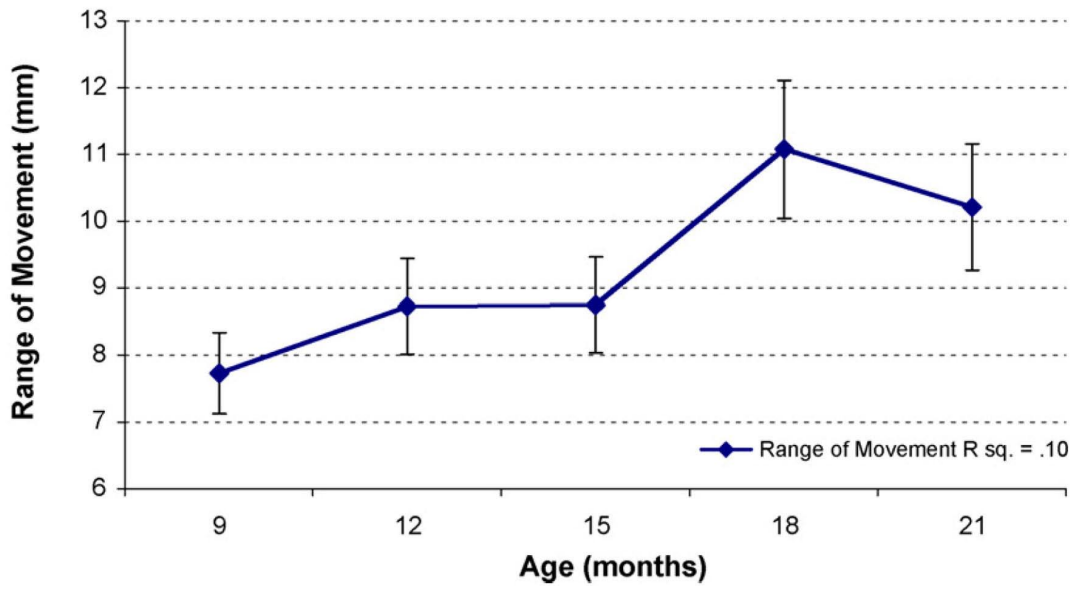

Figure 6. Range of movement of the lower lip marker from 9 to 21 months $(n=24)$. 


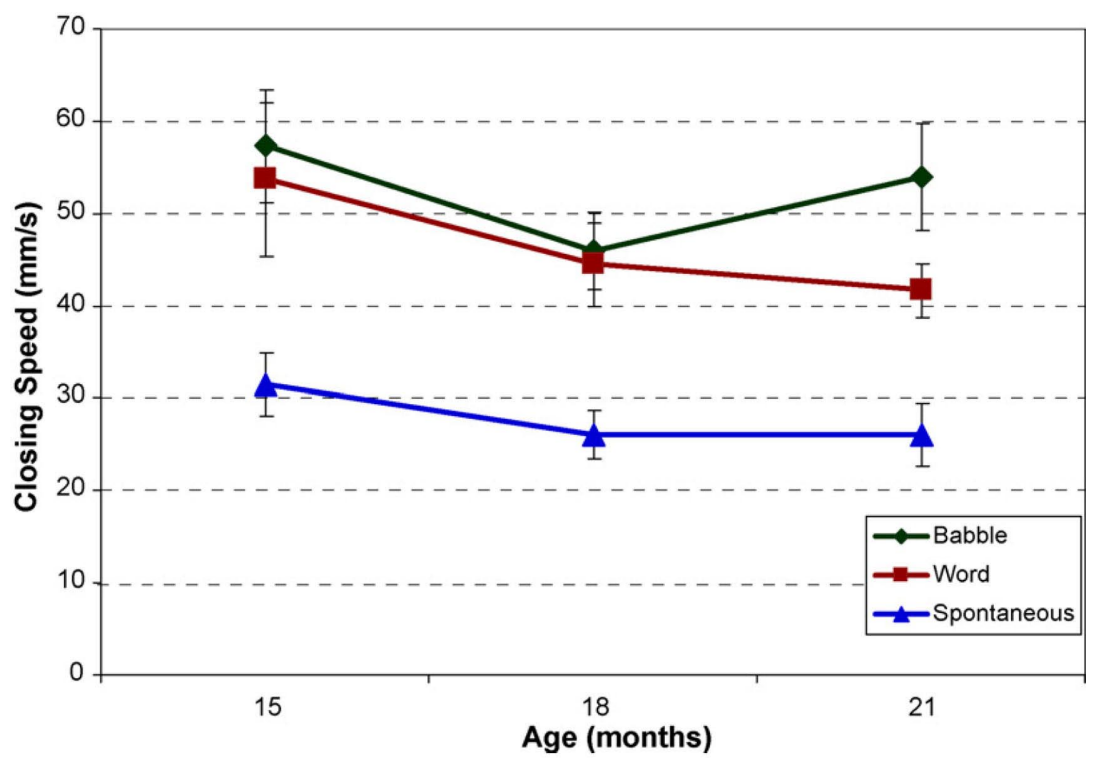

Figure 7. Closing speed of the jaw marker from 15 to 21 months $(n=24)$.

Table 1. ANCOVA for jaw marker closing speed $(n=24)$.

\begin{tabular}{lrrc}
\hline Source & Df & $F$ & $p$-value \\
\hline Orofacial behavior & 2 & 8.04 & .0008 \\
Age (covariate) & 1 & 3.61 & .06 \\
Age $\times$ behavior & 2 & .31 & .74 \\
Error & 154 & & \\
Total & 159 & & \\
\hline
\end{tabular}

Table 2. ANCOVA parameter estimates for jaw closing speed $(n=24)$.

\begin{tabular}{lrrrc}
\hline Parameter & Estimate & SE & $t$-value & $p$-value \\
\hline Fixed effects: & & & & \\
Intercept & 40.61 & 4.44 & 9.15 & $<.0001$ \\
Age & -1.87 & 1.12 & -1.67 & .06 \\
Behavior (word as comparison) & & & & .01 \\
$\quad$ Spontaneous movements & -16.04 & 6.25 & -2.57 & .18 \\
$\quad$ Babble & 8.57 & 6.26 & 1.37 & .58 \\
Interaction & & & .55 & .45 \\
$\quad$ Spontaneous $\times$ age & .85 & 1.54 & .76 & \\
Babble $\times$ age & 1.18 & 1.55 & &
\end{tabular}

$p<.0001]$ was significant. The solution using words as the comparison group indicated that babbles were not significantly different from words; however, silent spontaneous movements were significantly slower than words by $55.25 \mathrm{~mm} / \mathrm{s}$ at the age of 21 months $(t=-4.08, p=.0002)$. The age $\times$ orofacial behavior interaction was not significant (Table 4 ).

\section{Discussion}

The current investigation focused on the development of oral motor control during early speech and language acquisition from the ages of 9 to 21 months. Speeds of the opening and closing gestures of the lower lip and jaw increased with age. The developmental trajectories of jaw speed for silent spontaneous movements, babbles, and first words indicated that silent spontaneous movements were significantly slower than words. 


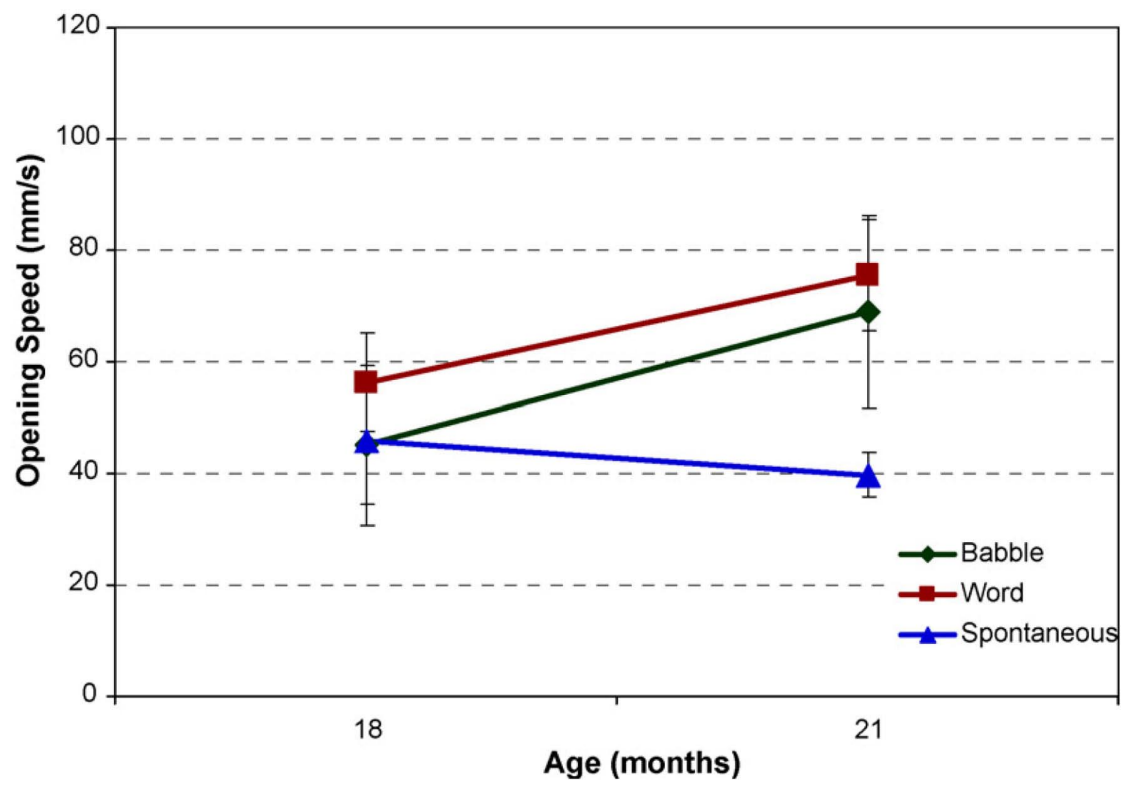

Figure 8. Closing speed of the lower lip marker from 18 to 21 months ( $n=15)$.

Table 3. ANCOVA for lower lip marker closing speed $(n=15)$.

\begin{tabular}{lrrc}
\hline Source & Df & $F$ & $p$-value \\
\hline Orofacial behavior & 2 & 13.48 & $<.0001$ \\
Age (covariate) & 1 & 3.19 & .10 \\
Age $\times$ behavior & 2 & 3.89 & .056 \\
Error & 46 & & \\
Total & 51 & & \\
\hline
\end{tabular}

Table 4. ANCOVA parameter estimates for jaw closing speed $(n=24)$.

\begin{tabular}{lcccc}
\hline & ANCOVA & & & \\
\cline { 2 - 5 } Parameter & Estimate & SE & $t$-value & $p$-value \\
\hline Fixed Effects: & & & & \\
Intercept & 93.76 & 9.89 & 9.52 & $<.0001$ \\
Age & 7.67 & 4.81 & 1.60 & .14 \\
Behavior (word as comparison) & & & & .0002 \\
$\quad$ Spontaneous movements & -55.25 & 13.54 & -4.08 & .58 \\
$\quad$ Babble & 7.62 & 13.54 & .56 & .07 \\
Interaction & & & -1.97 & .58 \\
$\quad$ Spontaneous $\times$ age & -12.79 & 6.50 & .58 & \\
$\quad$ Babble $\times$ age & 3.77 & 6.50 & & \\
\hline
\end{tabular}

\subsection{Orofacial behaviors overlap in development}

A variety of orofacial behaviors were observed at all ages studied. At the age of 9 months, more than half of the orofacial behaviors recorded were silent spontaneous movements, with the remainder of behaviors included babbles or vocalizations. At each session after 9 months, the number of silent spontaneous movements decreased. In contrast, babbles increased and peaked at 12 months before decreasing, and first words first appeared at 12 months and steadily increased. By 21 months of age, words were the vast majority of orofacial behaviors produced. Similar to findings of other studies (e.g., Moore \& Ruark, 1996), the current study shows that earlier-developing orofacial behaviors are produced long after the emergence of 
a new orofacial behavior. In addition, results indicated that silent spontaneous movements do continue to be produced up to 21 months of age.

\subsection{Orofacial movement speed increases with age}

The current findings demonstrated that articulatory speed increases in the jaw and lower lip from 9 to 21 months and support prior studies showing articulatory movement speed to increases from birth to adulthood. The speed of silent spontaneous movements for the upper lip, lower lip, and jaw increase during the first year of life (Green \& Wilson, 2006). This trend of increased speed with age continues past an infant's first birthday as prior studies have demonstrated that the combined lower lip and jaw speeds increase in a nonmonotonic fashion from childhood to adulthood (Nip \& Green, 2006; Smith \& Gartenberg, 1984; Walsh \& Smith, 2002).

The developmental increases in articulatory speed found in this study mirror speed increases in other motor systems. For example, arm tapping increases in speed with age and is associated with the speed of the fastest cortico-motoneuronal efferent nerves (Müller \& Hömberg, 1992). Although similar studies have not been conducted on the cortical pathways that control speech movements, there is some indirect evidence for developmental increases in neural conduction times of nerves innervating orofacial muscles. For example, the latency time for the perioral reflex has been shown to decrease from infancy to adulthood (Barlow, Finan, Bradford, \& Andreatta, 1993). Additional research is required to determine the extent that faster and more efficient motor conduction with age contributes to the observed gains in jaw and lower lip movement speeds.

Another potential reason for the age-related increases in speed is the increased proportion of babbles and words at later ages. The current findings demonstrate that words are produced with significantly faster speeds than are silent spontaneous movements and that infants produce more words and fewer spontaneous movements at later ages.

Although there was a net increase in lower lip and jaw movement speed with age, nonmonotonic trends were identified. Specifically, jaw and lower speed plateaued or decreased with age. Because these plateaus occurred at approximately the same time when vocabulary typically rapidly increases and phrases are beginning to be produced, follow-up studies are needed to investigate the temporal relations between the apparent cessation of age-related changes in articulatory speed and emerging language skills.

\subsection{Articulators develop at different rates}

Differences were observed in the developmental course of each articulator. A plateau in jaw speed was observed at 15 months, which was three months earlier than it was for lower lip speed. This finding is consistent with previous research suggesting that control over the jaw develops prior to control over the lips. For example, infants' jaw movements during imitation and reduplicated babble are highly similar to those of adults at the age of 12 months, whereas upper and lower lip movements become adultlike sometime between the ages of 2 and 6 years (Green et al., 2002).

Another difference found between the jaw and lower lip is that the range of movement of the lower lip was shown to increase with age; however, no similar age-related change was observed for the jaw. This increase in the range of movement may reflect the increasing involvement of lower movements to produce speech sounds that appears to occur between the ages of 12 and 24 months (Green et al., 2000). These results also parallel prior findings showing weak coupling between the movements of the lower lip and jaw during the first two years of life (Green et al., 2000).

\subsection{Differences among orofacial behaviors}

The current study also identified kinematic differences among the orofacial behaviors. The jaw and lower lip closing speeds produced during silent spontaneous orofacial movements were significantly slower than were those produced during words. This finding parallels reports from prior investigations showing differences between nonlinguistic and linguistic behaviors during early development in other speech subsystems. For example, the patterns of coupling during rest and speech breathing in toddlers are fundamentally different for rib cage and abdomen movements (Moore, Caulfield, \& Green, 2001), and for rib cage volumes and volume excursions (Boliek, Hixon, Watson, \& Morgan, 1996). Additionally, weaker coupling of mandibular muscle activation of toddlers has been observed during chewing than during words (Moore \& Ruark, 1996). In older children, movement speed is faster for tasks requiring greater cognition and language processing (Nip \& Green, 2006). 
Two explanations may account for the observed differences between nonlinguistic (i.e., silent spontaneous) and linguistic (i.e., words) behaviors in this study. The first is that each type of behavior may rely on distinct control mechanisms, similar to earlier studies that demonstrate differences between rest and speech breathing (Moore et al., 2001) and between chewing and speech (Moore \& Ruark, 1996). The second is that unlike silent spontaneous movements, babbling and words are goal-directed behaviors that require respiratory drive for phonation. Prior work has shown that speech with increased respiratory drive and vocal intensities (i.e., loud speech) is associated with faster articulatory speeds (Huber \& Chandrasekaran, 2006; Tasko \& McClean, 2004). Similarly, silent spontaneous movements may be produced with slower speeds than babbles and words because they require a relatively smaller degree of overall physiologic effort.

Although silent spontaneous movements are significantly different from words and babbles, these behaviors were not distinguished by their jaw or lower lip movement speeds. Strong similarities exist between the sounds used in babble and first words (de Boysson-Bardies, Sagart, \& Durand, 1984; Oller, Wieman, Doyle, \& Ross, 1975; [Stoel-Gammon, 1985; Vihman, 1986]), indicating continuity in phonological development between these two stages. The similarities in jaw speed for babbles and words are consistent with the continuity hypothesis at the kinematic level.

\section{Conclusions}

The current investigation examined the developmental trends of speech motor performance in young children and how these trends differ across orofacial behaviors. In this longitudinal study of typically developing children, jaw and lower lip movement speed increased between 9 and 21 months of age. Silent spontaneous movements were consistently slower than either babbles or words. This finding is consistent with the suggestion that linguistic demands affect speech movements. The current findings also corroborate prior suggestions that oral motor control develops at differing rates among articulators. Future studies will need to examine if the observed age-related changes in orofacial movements occur in articulators other than the lower lip and jaw. In addition, examining aspects of articulatory movement other than just speed and range of motion, will be essential for developing a more complete multifactorial, interactionist account of speech and language development.

\section{Acknowledgments}

This work has been supported by the National Institute of Health, National Institute on Deafness and Other Communication Disorders (R01 DC006463) and the Natural Sciences and Engineering Research Council of Canada Postgraduate Doctoral Scholarship (PGS D2-331510-2006). Additional support was provided by the Barkley Trust, University of Nebraska-Lincoln, Department of Special Education and Communication Disorders. The authors would like to thank Cynthia Didion, Lindsey Fairchild, Kimber Green, Lauren Head, Lacy LaBarge, Laura Maack, Antje Mefferd, Cory Quinlan, Kelly Raber, Paige Mueller, Cara Ullman, Kara Weaver, and Megan Wobken for their assistance with data collection and analysis.

\section{Appendix A. Continuing education (*correct answer)}

1. One reason for infants' limited phonetic repertoire may be: a. reduced articulatory control of the lips and tongue

b. reduced articulatory control of the jaw

c. (a) and (b)*

d. reduced articulatory of the tongue only

2. Advanced language skills is not associated with advanced speech motor skills:

a. True

b. False* 
3. The study used optical motion capture to record:

a. jaw movement

b. tongue movement

c. lower lip and jaw movement*

d. lip muscle activity

4. The study found that between 9 and 21 months:

a. the jaw and lower lip did not increase in speed

b. the jaw increased in speed but the lower lip did not show any increase in speed

c. the lower lip decreased in speed with age only

d. both the jaw and lower lip generally increased in speed*

5. When examining the movements for silent spontaneous movements, babbles, and words:

a. spontaneous movements were faster than words for the jaw

b. silent spontaneous movements were slower than words for the jaw and lower lip*

c. babbles were faster than both words and silent spontaneous movements

$\mathrm{d}$. there was no difference in speed between the three behaviors

\section{References}

Barlow et al., $1993>$ S. M. Barlow, D. S. Finan, P. T. Bradford and R. D. Andreatta, Transitional properties of the mechanically evoked perioral reflex from infancy through adulthood, Brain and Language 623 (1993), pp. 181-188.

Boliek et al., 1996 C. A. Boliek, T. J. Hixon, P. J. Watson and W. J. Morgan, Vocalization and breathing during the first year of life, Journal of Voice 10 (1996), pp. 1-22.

Carson et al., 2003 - C. P. Carson, T. Klee, D. K. Carson and L. K. Hime, Phonological profiles of 2-year olds with delayed language development: Predicting clinical outcomes at age 3, American Journal of Speech-Language Pathology 12 (2003), pp. 28-39.

Case-Smith, 1996 J. Case-Smith, Analysis of current motor development theory and recently published infant motor assessments, Infants and Young Children 9 (1996), pp. 29-41.

de Boysson-Bardies et al., 1984 B. de Boysson-Bardies, L. Sagart and C. Durand, Discernible differences in the babbling of infants according to target language, Journal of Child Language 11 (1984), pp. 1-15.

Dromey and Bates, 2005 C. Dromey and E. Bates, Speech interactions with linguistic, cognitive, and visuomotor tasks, Journal of Speech, Language, and Hearing Research 48 (2005), pp. 295-305.

Green et al., 2000 J. R. Green, C. A. Moore, M. Higashikawa and R. W. Steeve, The physiological development of speech motor control: lip and jaw coordination, Journal of Speech Language and Hearing Research 43 (2000), pp. 239-255.

Green et al., 2002 J. R. Green, C. A. Moore and K. J. Reilly, The sequential development of jaw and lip control for speech, Journal of Speech Language and Hearing Research 45 (2002), pp. 66-79.

Green and Nip, in press J. R. Green and I. S. B. Nip, Organization principles in the development of early speech: Catalysts, constraints, and synergy. In B. Maasen \& P. H. H. M. van Lieshout (Eds. ), Speech Motor Control: New Developments in Basic and Applied Research. NC: Oxford University Press (in press).

Green and Wilson, 2006 J. R. Green and E. M. Wilson, Spontaneous facial motility in infants: A 3D kinematic analysis, Developmental Psychobiology 48 (2006), pp. 16-28.

Hayes and Mitchell, $1998>$ M. J. Hayes and D. Mitchell, Spontaneous movements during sleep in children: Temporal organization and changes with age, Developmental Psychobiology 32 (1998), pp. 13-21.

Huber and Chandrasekaran, 2006 J. E. Huber and B. Chandrasekaran, Effects of increasing sound pressure level on lip and jaw movement parameter and consistency in young adults, Journal of Speech, Language, and Hearing Research 49 (2006), pp. 1368-1379.

Kent, 1992 R. D. Kent, The biology of phonological development. In: C. A. Ferguson, L. Menn and C. Stoel-Gammon, Editors, Phonological development: Models, research implications, York Press, Timonium, MD (1992), pp. 65-90.

Kent, 1999 R. D. Kent, Motor control: Neurophysiology and functional development. In: A. Caruso and E. Strand, Editors, Clinical Management of Motor Speech Disorders in Children, Thieme Medical Publishers, New York (1999).

Kleinow and Smith, 2006 J. Kleinow and A. Smith, Potential interactions among linguistic, autonomic, and motor factors in speech, Developmental Psychobiology 48 (2006), pp. 275-287.

Lewis, 2000 M. D. Lewis, The promise of dynamic systems approaches for an integrated account of human development, Child Development 71 (2000), pp. 36-43. 
Lopez Ramon and Cajal, 1996 Lopez Ramon and C. Cajal, Description of human fetal laryngeal functions: Phonation, Early Human Development 45 (1996), pp. 63-72.

MacNeilage et al., $2000>$ P. F. MacNeilage, B. L. Davis, A. Kinney and C. L. Matyear, The motor core of speech: A comparison of serial organization patterns in infants and languages, Child Development 71 (2000), pp. 153-163.

McShane, 1980 J. McShane, Learning to Talk, Cambridge University Press (1980).

Moore et al., 2001 C. A. Moore, T. J. Caulfield and J. R. Green, Relative kinematics of the rib cage and abdomen during speech and non-speech behaviors of 15 month-old children, Journal of Speech Language and Hearing Research 44 (2001), pp. 80-94.

Moore and Ruark, 1996 C. A. Moore and J. L. Ruark, Does speech emerge from earlier appearing oral motor behaviors?, Journal of Speech and Hearing Research 39 (1996), pp. 1034-1047.

Müller and Hömberg, $1992>$ K. Müller and V. Hömberg, Development of speed of repetitive movements in children is determined by structural changes in corticospinal efferents, Neuroscience Letters 144 (1992), pp. 57-60.

Nip and Green, 2006 I. S. B. Nip and J. R. Green, The development of speaking rate: A kinematic perspective, Paper presented at the Conference on Motor Speech Austin, TX (2006).

Oller, 2000 D. K. Oller, The Emergence of the Speech Capacity, Lawrence Erlbaum Associates, Mahwah, NJ (2000).

Oller et al., 1975 D. K. Oller, L. Wieman, W. Doyle and C. Ross, Infant babbling and speech, Journal of Child Language 3 (1975), pp. 1-11.

Paul and Jennings, $1992 \rightarrow$ R. Paul and P. Jennings, Phonological behavior in toddlers with slow expressive language development, Journal of Speech and Hearing Research 35 (1992), pp. 99-107.

Rescorla and Ratner, 1996 L. Rescorla and N. B. Ratner, Phonetic profiles of toddlers with specific expressive language impairment (SLI-E), Journal of Speech and Hearing Research 39 (1996), pp. 153-165.

Smith and Goffman, 2004 A. Smith and L. Goffman, Interaction of language and motor factors in speech production. In: B. Maasen, R. D. Kent, H. F. M. Peters, P. H. H. M. van Lieshout and W. Hulstijn, Editors, Speech motor control in normal and disordered speech, Oxford University Press (2004).

Smith and Gartenberg, 1984 B. L. Smith and T. E. Gartenberg, Initial observations concerning developmental characteristics of labio-mandibular kinematics, Journal of Acoustic Society of America 75 (1984), pp. 1599-1605.

Smith et al., 2006 B. L. Smith, K. K. McGregor and D. Demille, Phonological development in lexically precocious 2year olds, Applied Psycholinguistics 27 (2006), pp. 355-375.

Steeve et al., $2008-$ R. W. Steeve, C. A. Moore, J. R. Green, K. J. Reilly and J. Ruark McMurtrey, Babbling, chewing, and sucking: Oromandibular coordination at 9 months, Journal of Speech, Language, and Hearing Research 51 (2008), pp. 1390-1404.

Stoel-Gammon, 1985 C. Stoel-Gammon, Phonetic inventories, 15-24 months: A longitudinal study, Journal of Speech and Hearing Research 28 (1985), pp. 505-512.

Stoel-Gammon, 1998 C. Stoel-Gammon, Role of babbling and phonology in early linguistic development. In: A. M. Wetherby, S. F. Warren and J. Reichle, Editors, Transitions in Prelinguistic Communication, vol. 7, Paul H. Brookes Publishing Co., Baltimore (1998), pp. 87-110.

Sussman et al., 1996 H. M. Sussman, F. D. Minifie, E. H. Buder, C. Stoel-Gammon and J. Smith, Consonant-vowel interdependencies in babbling and early words: Preliminary examination of a locus equation approach, Journal of Speech and Hearing Research 39 (1996), pp. 424-433.

Tasko and McClean, 2004 S. M. Tasko and M. D. McClean, Variations in articulatory movement with changes in speech task, Journal of Speech Language and Hearing Research 47 (2004), pp. 85-100.

Thelen, 1991 E. Thelen, Motor aspects of emergent speech: A dynamic approach. In: N. A. Krasnegor, D. M. Rumbaugh, R. L. Schiefelbusch and M. Studdert-Kennedy, Editors, Biological and Behavioral Determinants of Language Development, Erlbaum, Hillsdale, NJ (1991), pp. 339-362.

Vihman, 1986 M. M. Vihman, Individual differences in babbling and early speech: predicting to age three. In: B. Lindblom and R. Zetterstrom, Editors, Precursors of Early Speech, vol. 44, Stockton Press, New York (1986), pp. 95-109.

Walsh and Smith, $2002 \rightarrow$ B. Walsh and A. Smith, Articulatory movements in adolescents: Evidence for protracted development of speech motor control processes, Journal of Speech, Language, and Hearing Research 45 (2002), pp. 1119-1133.

Whitehurst et al., $1991>$ G. J. Whitehurst, M. Smith, J. E. Fischel, D. S. Arnold and C. J. Lonigan, The continuity of babble and speech in children with specific expressive language delay, Journal of Speech and Hearing Research 34 (1991), pp. 1121-1129. 